\title{
Anthropogenic Pollution Intervenes the Recovery Processes of Soil Archaeal Community Composition and Diversity From Flooding
}

\author{
Yu Wang ${ }^{1}$, Yiguo Hong ${ }^{1}$, Maohua $\mathrm{Ma}^{2}$, Shengjun $\mathrm{Wu}^{2}$, Huub J. M. Op den Camp ${ }^{3}$, \\ Guibing Zhu ${ }^{4}$, Wei Zhang ${ }^{2 *}$ and Fei Ye ${ }^{1 *}$ \\ 1 Institute of Environmental Research at Greater Bay Area, Key Laboratory for Water Quality and Conservation of the Pearl \\ River Delta, Ministry of Education, Guangzhou University, Guangzhou, China, ${ }^{2}$ Chongqing Institute of Green and Intelligent \\ Technology, Chinese Academy of Sciences, Chongqing, China, ${ }^{3}$ Department of Microbiology, Institute for Water \\ and Wetland Research, Radboud University Nijmegen, Nijmegen, Netherlands, ${ }^{4}$ Key Laboratory of Drinking Water Science \\ and Technology, Research Center for Eco-Environmental Sciences, Chinese Academy of Sciences, Beijing, China
}

OPEN ACCESS

Edited by:

Jaak Truu,

University of Tartu, Estonia

Reviewed by:

Jonathan Adams,

Cranfield University, United Kingdom

Simone Raposo Cotta,

University of São Paulo, Brazil

${ }^{*}$ Correspondence: Wei Zhang

zhangwei@cigit.ac.cn

Fei Ye

yefei09007@gzhu.edu.cn

Specialty section:

This article was submitted to

Terrestrial Microbiology,

a section of the journal

Frontiers in Microbiology

Received: 03 April 2019

Accepted: 19 September 2019

Published: 02 October 2019

Citation:

Wang Y, Hong Y, Ma M, Wu S,

Op den Camp HJM, Zhu G, Zhang W and Ye F (2019) Anthropogenic

Pollution Intervenes the Recovery

Processes of Soil Archaeal

Community Composition

and Diversity From Flooding.

Front. Microbiol. 10:2285.

doi: 10.3389/fmicb.2019.02285
Archaea play vital roles in global biogeochemical cycles, particularly in nitrification and methanogenesis. The recovery of archaeal community following disturbance is essential for maintaining the stability of ecosystem function. To examine whether the archaeal community could recover from water flooding and assess the influence of anthropogenic pollution on the autogenic recovery, soil samples from two riparian zones with contrasting pollution background were investigated. Collected samples in each area were divided into three groups of reference, flooding, and recovery according to the flooded state of each site. The results showed that the archaeal abundance was resilient to the disturbances of both water flooding and anthropogenic pollution. More similar community composition and diversity appeared between the recovery and reference groups in the area with low anthropogenic pollution. It indicated that high anthropogenic pollution could result in less resilience of archaeal community. The co-occurrence network further revealed that the archaeal community in the area of low anthropogenic pollution exhibited more associations suggesting a higher ecosystem stability. The better recovery of archaeal community was associated with the high resilience ability. The Nitrososphaerales was the key taxon maintaining the better recovery of the archaeal community from the disturbances due to its high resilience index and quantitative dominance. Overall, archaeal community has the capability of autogenic recovery, the process of which might be intervened by anthropogenic pollution, and then potentially affects the ecosystem functions of the riparian system.

Keywords: archaea, autogenic recovery, disturbance, human impact, riparian zone, three gorges reservoir

\section{INTRODUCTION}

Microbial community composition is critical for predicting rates of ecosystem processes, which is often ignored comparing with plant (Allison and Martiny, 2008). In fact, microbial communities respond more rapidly than plant communities to changing environmental conditions (Harris, 2009), and play central roles in ecosystem processes in many ways, such as driving the 
Earth's biogeochemical cycles (Griffiths and Philippot, 2013), affecting plant productivity and community dynamics (Wardle et al., 2004; van der Heijden et al., 2008), and re-establishing function and microbial diversity in ecosystem restoration (Harris, 2009). Recovery after being disturbed is essential for microbe, since most natural environments are subject to disturbances over time. The measurements of soil microbial community structure and composition are increasingly being applied to assess the response of ecosystems to disturbances and as an indicator of ecosystem recovery (Harris, 2003; van Dijk et al., 2009; Lewis et al., 2010). Detailing the response of microbial communities to disturbances and the recovery processes are important to understand the associations between microbial community structure and functional properties of ecosystems (Yannarell et al., 2007).

Disturbances in soil environment refer to the changes in physical or chemical condition (especially from anthropogenic sources) (Glasby and Underwood, 1996). In the context of global change, four types of disturbance have been frequently studied: increased $\mathrm{CO}_{2}$ concentrations, temperature changes, mineral fertilization $(\mathrm{N} / \mathrm{P} / \mathrm{K})$, and enrichment with $\mathrm{C}$ substrates (Allison and Martiny, 2008). More than $80 \%$ of the mineral fertilization, temperature, and $\mathrm{C}$ amendment researches observed significant impacts of disturbances on microbial composition (Allison and Martiny, 2008). An effect of elevated $\mathrm{CO}_{2}$ concentrations was found as many as $60 \%$ of the studies (Allison and Martiny, 2008). In addition, the dry/wet cycles represent another common disturbance on soil microbial communities, which was predicted to grow more influential with future climate change (Bapiri et al., 2010). The dry/wet cycles occur in many occasions like irrigation in agricultural soil (Burger et al., 2005), precipitation in arid and semiarid ecosystems (Sponseller, 2007), and water fluctuation in riparian soil (Wang et al., 2016). One of the most well-known consequences is that the soil microbial biomass and its activity increase sharply after rewetting, and then a large amount of gaseous carbon and nitrogen erupt from the soil, named as "Birch effect" (Birch, 1958). Hence, the anthropogenic disturbance and dry/wet cycles are two major environmental disturbances regulating the soil microbial composition and dynamics.

Microbial communities respond to environmental disturbance differently, restructuring the microbial communities is the most common response (Vellend, 2010). In other cases, resistance and resilience are two patterns of microbial community response to disturbances: resistance means that microbial composition could remain unchanged after disturbance due to a high degree of metabolic flexibility or physiological tolerance (Meyer et al., 2004); while resilience means that even if microbial communities do change as a result of disturbance, the communities might quickly return to its composition before disturbance (Allison and Martiny, 2008). Previous studies investigated the influence of one individual disturbance (e.g., hurricane, drying-rewetting cycles, compaction, and fire) to soil microbial community (Yannarell et al., 2007; Bapiri et al., 2010; Hartmann et al., 2014; Lee et al., 2017). Actually, current threats to soil microbial community are usually a consequence of different sources of co-occurring disturbances that operate synergistically. When facing a joint effect of disturbances, how do the microbial community and recovery process respond are poorly understood.

Three Gorges Dam is the most important hydroelectric project along Yangtze River (Nilsson et al., 2005; Shi, 2011; Xu et al., 2011). The riparian zone of the three gorges reservoir (TGR) is directly impacted by the periodical fluctuation of water level, which is impounded to $175 \mathrm{~m}$ in winter and discharged to $145 \mathrm{~m}$ in summer in one consecutive inundation cycle (China Three Gorges Corporation, 2017). The frequent and dramatic water level fluctuation in the riparian zone modify the quantity of available nutrients (Ye et al., 2015), and reduce oxygen availability in the soil thereby controlling microbial community composition and function (Wu et al., 2015). As an aggravating factor, the direct discharge of industrial and domestic sewage without treatment also intensify the enrichment of nutrient substances in the riparian soils (Su and Zhang, 2010; Xian et al., 2013), and are acting synergistically with disturbance from water level fluctuation.

In this study, we targeted the archaeal community in the riparian zone of the TGR, and hypothesized that (i) the archaeal community had the ability to recover from the disturbances and (ii) the recovery process of the archaeal community might be affected by the joint effect of those two disturbances. To test these hypotheses this study (i) examined whether archaeal community has the ability of autogenic recovery in riparian zones; (ii) assessed the recovery of archaeal communities from flooding in riparian zones with contrasting anthropogenic pollution levels; and (iii) revealed the key taxa with properties of resistance and resilience in the recovery process. To achieve these, we specifically applied multi-step approaches to cover different potentially useful microbial indicators including the quantification of archaea by quantitative PCR (qPCR), the community description via amplicon sequencing analysis followed by the calculation of resilience and resistance indices, and the description of the community organization and potential interactions via network analysis.

\section{MATERIALS AND METHODS}

\section{Study Area and Sampling Strategy}

The soil in the riparian zone of this study is submerged for 39273 days depending on elevation. While the water level starts to drop, the submerged soil re-exposes and returns to an unflooded state (Supplementary Table S1). Two riparian zones with entirely contrasting intensities of anthropogenic pollution (Figure $\mathbf{1}$ and Supplementary Table S2) were chosen: (i) Baijiaxi riparian zone $\left(31^{\circ} 09^{\prime} 02^{\prime \prime} \mathrm{N}, 108^{\circ} 33^{\prime} 45^{\prime \prime} \mathrm{E}\right)$ and (ii) Xiaohe riparian zone $\left(31^{\circ} 07^{\prime} 37^{\prime \prime} \mathrm{N}, 108^{\circ} 28^{\prime} 35^{\prime \prime} \mathrm{E}\right)$. The Baijiaxi area located in a wetland nature reserve, where the limited population pressure triggers much less anthropogenic pollution, is taken as a natural area (NA) in this study. The Xiaohe area is close to a village about $7.5 \mathrm{~km}$ upstream of Baijiaxi area. Due to the imperfect drainage system, large amounts of untreated sewage in Xiaohe are discharged into the adjacent river through the riparian zone. Furthermore, the nearby livestock and poultry breeding further intensify the pollutant input into Xiaohe area, which represents 

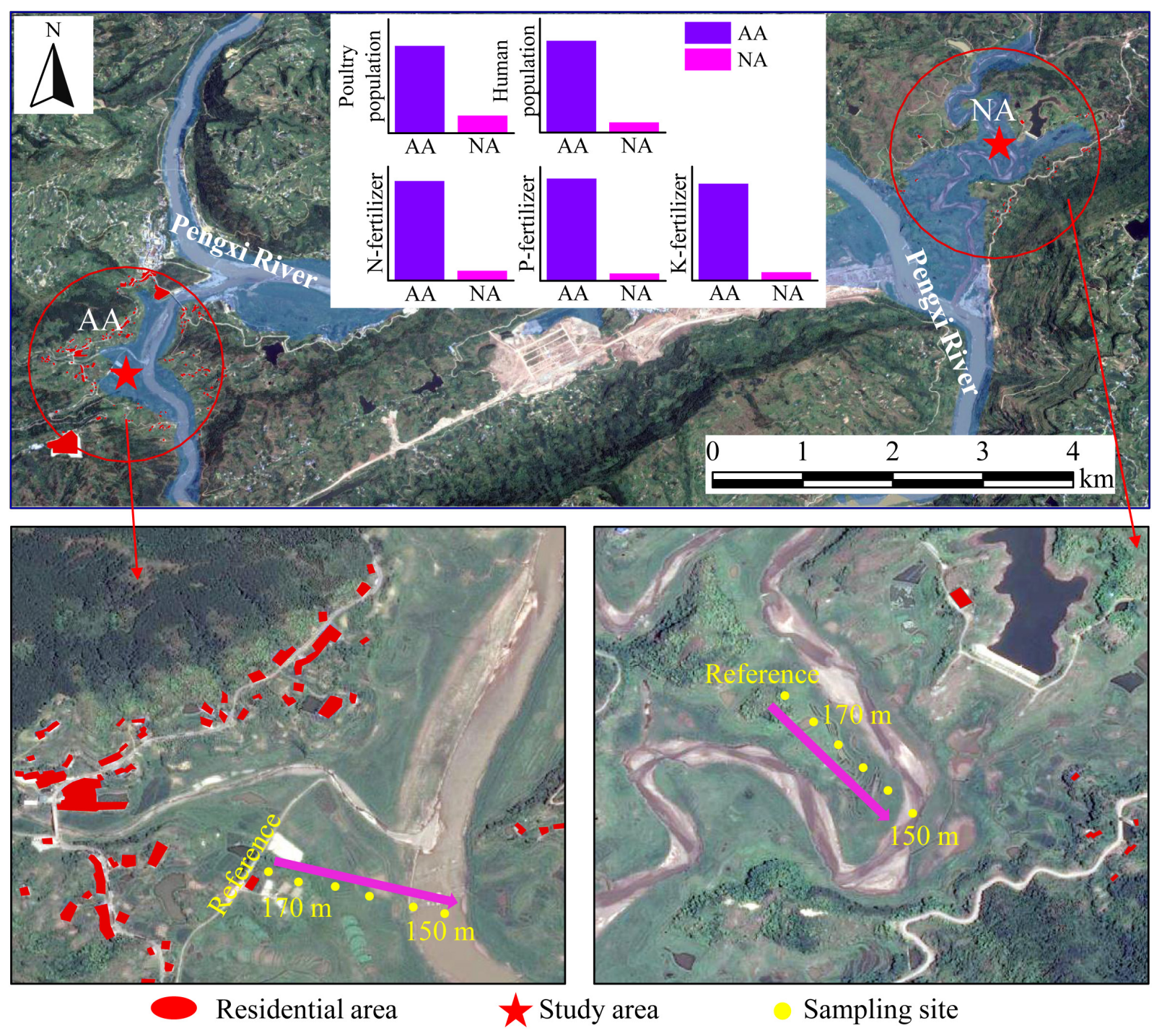

FIGURE 1 | Location of the study areas (red stars). The residential areas around NA and AA within $1 \mathrm{~km}$ (red circles) are highlighted in red. The extent of the flooded riparian zone upon reaching the highest water level is shown in blue background. Along an elevation gradient of 150-170 m, sampling sites were set up at $5 \mathrm{~m}$ intervals. Samples taken at $175.5 \mathrm{~m}$, soil not flooded, were used as reference for undisturbed soil. The bar charts indicate the different intensities of anthropogenic pollution in NA and AA represented by poultry population, human population, and fertilizing amount, the data of which are presented in Supplementary Table S2.

an anthropogenic area (AA) in this study. In addition, the two study areas are characterized by similar zonal soil type, soil texture, and meteorological conditions (Ye et al., 2019).

The water level in both the NA and AA fluctuates periodically between the highest level of 174-175 $\mathrm{m}$ and the lowest level of $150 \mathrm{~m}$. To take advantage of the in situ flooding gradient, samples were taken at $5 \mathrm{~m}$ intervals in a transect along the elevational gradient. A total of four sampling surveys were conducted at October 10, 2013 and April 1, 2014, September 23, 2014, and May 6, 2015, representing the beginning and later stages of water flooding in two consecutive inundation cycles (Supplementary Figure S1).

Referred to previous study (Lee et al., 2017), 24 collected samples in both NA and AA were divided into three groups: samples collected from the unflooded sites of $175.5 \mathrm{~m}$ were set as reference group; and sites below the water level were set as flooding group; the sites which were flooded previously and were above the water level when sampling were set as recovery group (Supplementary Table S1). A total of 4 reference soils, 7 recovery soils, and 13 flooding affected soils were taken in each study area. Soil samples from 0 to $10 \mathrm{~cm}$ depth were collected using a stainless-steel core sampler and a Petersen grab for samples above and below water level, respectively. Bare surface soil samples were taken to minimize the impacts of plants and to maximize the comparability between samples. Subsamples were collected in triplicate at each sampling site, and then mixed thoroughly to form one composite sample. A portion of each composite soil sample was stored at $4^{\circ} \mathrm{C}$ for physicochemical 
analysis, and the remaining soil was stored at $-20^{\circ} \mathrm{C}$ before nucleic acid extraction.

\section{Determination of Soil Physicochemical Properties}

Soil $\mathrm{pH}$ was determined at a soil to milliQ water ratio of 1:5 using a $\mathrm{pH}$ analyzer. Soil moisture was measured using gravimetric method with $105^{\circ} \mathrm{C}$ oven-drying for $48 \mathrm{~h}$. $\mathrm{NH}_{4}^{+}$ and $\mathrm{NO}_{3}^{-}$were extracted from soil with $2 \mathrm{~mol} \mathrm{~L}^{-1} \mathrm{KCl}$ at a soil to solution ratio of $1: 5$, and then measured using a flow injection analyzer (FIA Star 5000, FOSS Tecator, Sweden). The contents of total carbon (TC), total nitrogen (TN), total sulfur (TS), and the $\mathrm{C} / \mathrm{N}$ ratio in soils were determined with an element analyzer (Vario EL cube, Elementar, Germany). Organic matter (OM) was analyzed through loss-on-ignition method at $550^{\circ} \mathrm{C}$ (Dean, 1974). Soil ferrous iron $\left(\mathrm{Fe}^{2+}\right)$ was extracted with $0.1 \mathrm{~mol} \mathrm{~L}^{-1} \mathrm{Al}_{2}\left(\mathrm{SO}_{4}\right)_{3}$ solution at $\mathrm{pH}$ of 2.5 , and the $\mathrm{Fe}^{2+}$ concentration in the supernatants was measured colorimetric using $o$-phenanthroline at $520 \mathrm{~nm}$ absorbance (UV1750, Shimadzu, Japan). The $\mathrm{Fe}^{3+}$ concentration resulted from the difference between hydroxylamine hydrochloride reduced $\mathrm{Fe}^{2+}$ and $\mathrm{Fe}^{2+}$ measured directly [Bao, 2000 (In Chinese)]. Since the $\mathrm{Fe}^{2+}-\mathrm{Fe}^{3+}$ system often acts as an electron carrier, we employed the $\mathrm{Fe}^{2+} / \mathrm{Fe}^{3+}$ ratio as an indicator for estimating the redox environment in soil (Zheng et al., 2001). All analyses were performed in triplicate.

\section{DNA Extraction and Quantitative PCR}

Approximately $0.25 \mathrm{~g}$ soil was used to extract DNA from each sample using the PowerSoil DNA Isolation Kit (Mobio, United States). The quantity and quality of extracted DNA were checked with a NanoVue Plus Spectrophotometer (GE Healthcare, United Kingdom). The abundance of the 16S rRNA gene of archaea was measured in triplicate on a Mastercycler (Eppendorf, Germany) with specific primer pairs A364aFA934bR (Burggraf et al., 1997; Großkopf et al., 1998). Standard curve was built using a 10 -fold serial dilution of plasmids containing the targeted fragments of archaeal 16S rRNA gene. Each qPCR reaction contained $10 \mu \mathrm{L}_{\text {SYBR }}{ }^{\circledR}$ Premix Ex Taq ${ }^{\mathrm{TM}}$ II (Takara, Japan), $0.8 \mu \mathrm{L}$ of each primer $\left(10 \mathrm{pmol} \mu \mathrm{L}^{-1}\right), 1 \mu \mathrm{L}$ DMSO, and $1 \mu \mathrm{L}$ of template. qPCR assay was as follow: $95^{\circ} \mathrm{C}$ for $2 \mathrm{~min}$, followed by 40 cycles of $95^{\circ} \mathrm{C}$ for $20 \mathrm{~s}, 63^{\circ} \mathrm{C}$ for $60 \mathrm{~s}$, and $68^{\circ} \mathrm{C}$ for $60 \mathrm{~s}$ (Ye et al., 2016). The qPCR efficiencies were 84.0-92.1\% $\left(R^{2}>0.990\right)$.

\section{Sequencing and Processing of Archaeal 16S rRNA Genes}

The V3-V5 region of the archaeal 16S rRNA gene was amplified by PCR using primers Arch344F (5'-barcodeACGGGGYGCAGCAGGCGCGA-3' ${ }^{\prime}$ and Arch915R (5'-GTGCTCCCCCGCCAATTCCT-3') (Bernd et al., 2012). The PCR products were gel purified using the AxyPrep DNA Gel Extraction Kit (Axygen, United States). Subsequently, purified amplicons were pooled in equal amounts and paired-end sequenced on an Illumina MiSeq PE300 platform ${ }^{1}$. Samples

${ }^{1}$ http://www.Majorbio.com at $160 \mathrm{~m}$ elevation were excluded from high-throughput sequencing analysis due to the very close flooding/exposure rotation with that of $165 \mathrm{~m}$.

Raw sequence data were conducted using Trimmomatic (version 0.30). The merged sequences were quality-filtered, and sequences which could not meet the following parameters were discarded: sequence length $<300 \mathrm{bp}$, average quality score $\geq 20$ over a $50 \mathrm{bp}$ sliding window, and no ambiguous bases. Operational taxonomic units (OTUs) were picked at 97\% sequence similarity using the standard UPARSE pipeline within USEARCH (vsrsion 7.02). Taxa were identified with SILVA rRNA database (Release $128^{3}$ ). The phylogenetic analysis of dominant taxa sequences (relative abundance $>1 \%$ ) was conducted using FastTree (version 2.1.3) based on approximately maximumlikelihood. To compare archaea community diversity in different samples/groups on an equal basis, sequences (20,826-41,684 reads per sample) were rarefied to 20,826 reads per sample according to the sample with the lowest number of reads.

\section{Nucleotide Sequence Accession Number}

The Illumina sequencing data were submitted to the NCBI Sequence Read Archive $e^{4}$ under accession No. PRJNA394057.

\section{Statistical Analysis}

Alpha diversity (Shannon diversity, Chaol richness, and Shannon-based species evenness) and rarefaction analysis were calculated using Mothur (version v.1.30.1) based on the rarefied sequence data. The differences in soil properties between study areas were conducted with Mann-Whitney $U$-test using SPSS Statistics 20.0 for Windows (IBM, United States). The differences of archaeal abundance, alpha diversity, and among groups were calculated based on multiple Kruskal-Wallis using SPSS Statistics 20.0 for Windows (IBM, United States). Analysis of similarity (ANOSIM; permutations $=999$ ) was used to compare the archaeal community (OTU level) among groups based on BrayCurtis distance using program $\mathrm{R}$ version 3.0.1 (vegan package). Redundancy analyses (RDAs) of archaeal community structures (OTU level) and correlations with soil properties were performed using the CANOCO 5 software based on log-transformed data. Graphs were generated using ORIGIN 9.0 software.

\section{Calculation of Resistance and Resilience}

The resistance (RS) and resilience (RL) indices were employed to quantitatively assess the response of the archaeal community to disturbance. The RS index was calculated for archaea gene abundance and diversity, accounting for differences caused by a disturbance, using the following equation (Orwin and Wardle, 2004):

$$
\mathrm{RS}=1-\frac{2\left|C_{0}-P_{0}\right|}{\left(C_{0}+\left|C_{0}-P_{0}\right|\right)}
$$

where $C_{0}$ and $P_{0}$ are the values of variables in the reference and flooding groups, respectively. The values of RS range between

\footnotetext{
${ }^{2}$ http://drive5.com/uparse/

${ }^{3} \mathrm{http}: / /$ www.arb-silva.de

${ }^{4} h t t p: / / w w w . n c b i . n l m . n i h . g o v / s r a /$
} 
-1 and +1 with +1 representing no effect of disturbance (maximal resistance).

The RL index was calculated for the same variables after disturbance according to equation as (Orwin and Wardle, 2004):

$$
\mathrm{RL}(x)=\frac{2\left|C_{0}-P_{0}\right|}{\left(\left|C_{0}-P_{0}\right|+\left|C_{x}-P_{x}\right|\right)}-1
$$

where $C_{0}$ was equal to $C_{x}$ in this study, which is the values of variables in the reference groups. $P_{0}$ and $P_{x}$ are the values of those variables in the flooding and recovery groups, respectively. The values of $R L$ also range between -1 and +1 with +1 represents complete recovery (maximal resilience).

\section{Network Analysis}

Network analysis was carried out to reveal the co-occurrence patterns of archaeal communities in different study areas. To visualize the associations in networks, correlation matrixes were constructed by calculating the possible pairwise Spearman's rank correlations based on genus level (Faust and Raes, 2012). The Spearman's rank correlation coefficient $(\rho)$ absolute value $>0.6$ and the $P$-value $<0.01$ was considered as a statistically robust correlation between genera (taxa) ( $\mathrm{Hu}$ et al., 2016). The nodes and edges in the networks represented archaeal taxa and strong correlations between nodes, respectively. Topological characteristics of the networks were used to describe the associations among archaeal taxa (Ma et al., 2016). The Spearman's rank correlations were calculated with Python 2.6, and networks were visualized with Gephi (Bastian et al., 2009).

\section{RESULTS}

\section{Soil Properties in NA and AA}

The higher anthropogenic impact in AA increased the content of $\mathrm{OM}, \mathrm{TC}, \mathrm{TN}$, and $\mathrm{C} / \mathrm{N}$ ratio significantly (Mann-Whitney $U$-test, $P<0.05$, Figure 2). No significant difference on $\mathrm{NH}_{4}^{+}, \mathrm{NO}_{3}^{-}, \mathrm{TS}$, $\mathrm{Fe}^{2+} / \mathrm{Fe}^{3+}, \mathrm{Fe}^{2+}, \mathrm{Fe}^{3+}$, and moisture was observed between the two areas (Figure 2). The soil $\mathrm{NO}_{3}^{-}, \mathrm{OM}, \mathrm{TN}, \mathrm{C} / \mathrm{N}$, and $\mathrm{Fe}^{3+}$ in the dry (recovery) soils did not show significant difference with the flooding soils in both areas (Mann-Whitney $U$-test, $P>0.05$, Supplementary Figure S2). Besides, water flooding significantly increased the soil TC, TS, $\mathrm{Fe}^{2+} / \mathrm{Fe}^{3+}$, and $\mathrm{Fe}^{2+}$ in AA (MannWhitney $U$-test, $P<0.05$ ), whereas no significant differences were observed in NA (Supplementary Figure S2).

\section{Archaeal Abundance and Diversity in Different Sample Groups}

The average archaeal abundance in the NA flooding group was $1.9 \times 10^{9}$ copies (g d.w.s., gram dry weight soil) ${ }^{-1}$, and no significant difference from the recovery and reference groups was observed (multiple Kruskal-Wallis test, $P>0.05$, Figure 3A). By contrast in AA, the flooding group showed the highest abundance on average $\left[1.2 \times 10^{9}\right.$ copies $\left.(\mathrm{g} \text { d.w.s. })^{-1}\right]$, which was significantly higher than in the recovery group (multiple Kruskal-Wallis test, $P=0.013$ ). In general, the average abundances in the recovery groups were close to those of the reference groups both in NA and AA $\left[4.6 \times 10^{8} \text { vs. } 8.6 \times 10^{8} \text { copies (g d.w.s. }\right)^{-1}$ and $2.1 \times 10^{8}$ vs. $3.2 \times 10^{8}$ copies $(\mathrm{g} \text { d.w.s. })^{-1}$ ].

Archaeal alpha diversity indices within the different flooding groups were generally higher than those of the reference groups in both NA and AA (Figure 3B). The Shannon diversity, Shannon evenness, and Chaol richness in the recovery group were generally in between the flooding and reference groups; however, different patterns were observed in the two study areas. In NA, significant difference (multiple Kruskal-Wallis test, $P=0.027$ ) was observed between the recovery and flooding groups on Shannon diversity, while no significant difference was observed between the recovery and reference group. Contrarily, in AA Shannon evenness and Shannon diversity in the recovery group differed significantly from those in the reference group (multiple Kruskal-Wallis test, $P<0.01$ ). Therefore, the recovery soil in NA was more comparable to the reference soil with respect to alpha diversity.

\section{Archaeal Community Composition in NA and $A A$}

The most abundant taxa (primarily at the family/genus level; relative abundance $>1 \%$ ) across all NA sample groups accounted for $92.7 \%$ of all sequences (Figure $4 \mathbf{A}$ ). Water level fluctuation and the resulting periodical exposure to air in particularly affected the proportion of ammonia-oxidizing archaea and methanogens. The relative abundance of ammonia-oxidizing archaea, which was the main component of Thaumarchaeota, increased from $38.9 \%$ in the flooding group to $75.8 \%$ in the recovery group and $95.7 \%$ in the reference group in NA (Supplementary Figure S3). In contrast, the euryarchaeotal methanogens decreased in the reference $(3.1 \%)$ and recovery $(20.8 \%)$ groups compared to the flooding group (47.6\%, Supplementary Figure S3).

In AA, the most abundant taxa represented $95.7 \%$ of total sequences (Figure 4A). The Thaumarchaeota represented 37.8 and $47.6 \%$, the Euryarchaeota represented 44.3 and $36.3 \%$, and the Bathyarchaeota corresponded to 6.4 and $10.1 \%$ of the total sequences in flooding and recovery groups, respectively (Supplementary Figure S4). In the reference group, the proportions of those three phyla (Thaumarchaeota, Euryarchaeota, and Bathyarchaeota represented 93.6, 2.9, and $0 \%$, respectively) were largely different from the flooding and recovery groups. The relative abundance of ammonia-oxidizing archaea in the reference group in AA was $93.6 \%$, which decreased to $46.7 \%$ in the recovery group and $35.6 \%$ in the flooding groups (Supplementary Figure S3). Similarly to NA, the methanogens had the lowest relative abundance in the reference group, and increased to $30.5 \%$ in the recovery group and $34.6 \%$ in the flooding groups (Supplementary Figure S3).

Redundancy analysis was used to compare the community structure across the sample groups in NA and AA. The archaeal communities in the flooding group appeared to be less related to each other than the communities in the other two groups. The sampling sites in the two study areas were at least partly clustered according to the sample group (Figure 4B). This separation was in particular evident for NA, where the community structure was mostly governed by the sampling elevation (forward selection 

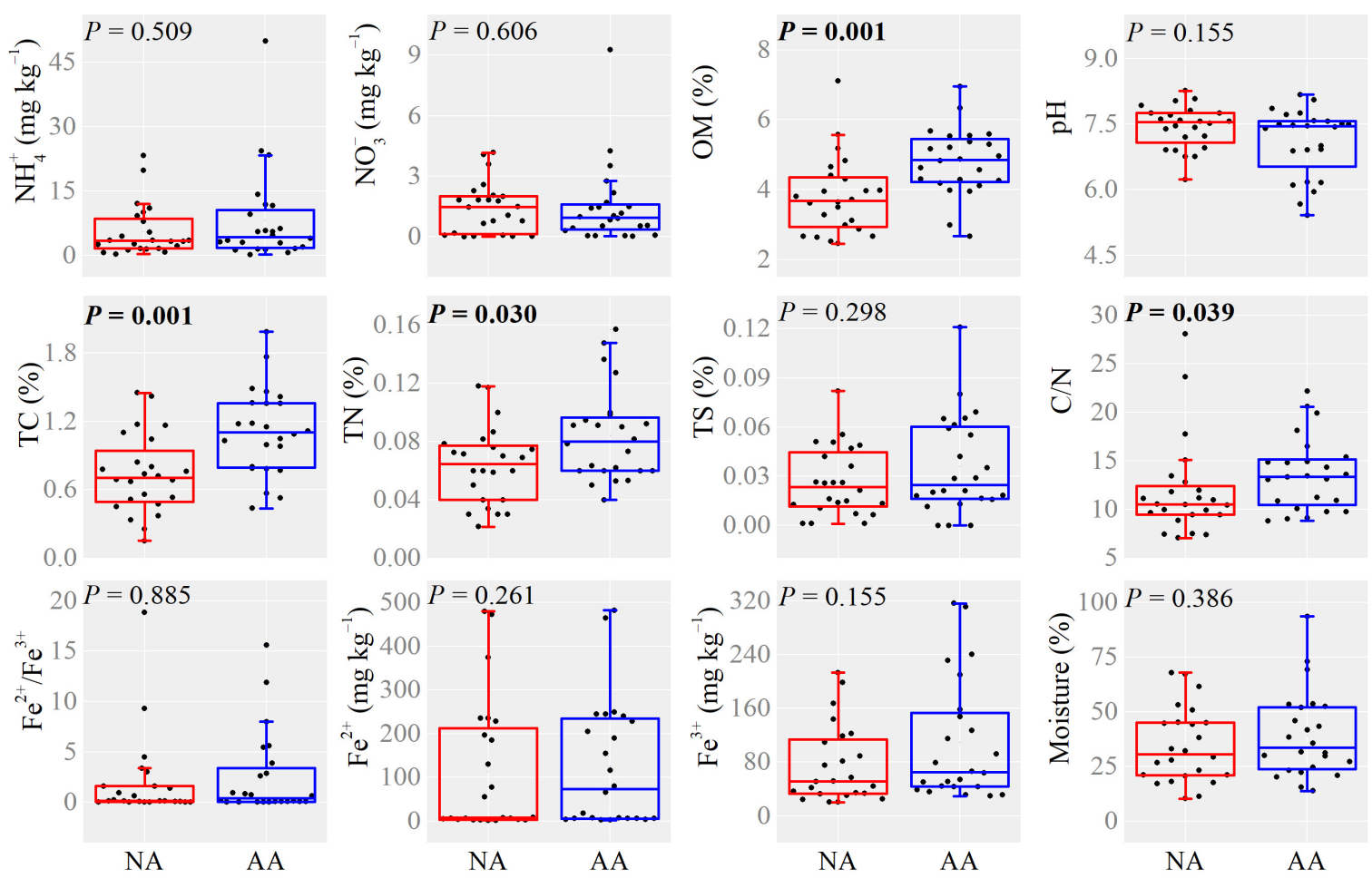

FIGURE 2 | Boxplots of soil properties in NA and AA. Single dot represents the average value in each sampling elevation. $P$-values in bold indicate significant differences at 0.05 level based on Mann-Whitney $U$-test.

pseudo $F=8.60, P=0.001$ ) and the associated flooding duration (AFD, days) (forward selection pseudo $F=1.60, P=0.045$ ). In contrast, the flooding and recovery sites in AA grouped distantly from the reference sites.

Community compositions on OTU level were further compared between the three groups by an ANOSIM similarity test (Table 1). The community compositions of the flooding groups were significantly different from the reference groups both in NA $(R=0.504, P=0.002)$ and AA $(R=0.340, P=0.027)$. The recovery group in NA differed significantly $(R=0.307$, $P=0.010)$ from the flooding group, while no significant difference was observed between the recovery and reference groups $(R=0.147, P=0.154)$, which indicated more similar community compositions between the recovery and reference groups. In AA, the recovery group was significantly different from the flooding group $(R=0.228, P=0.033)$ and reference group $(R=0.564, P=0.011)$, and showed a stronger difference from the reference group according to the higher $R$-value.

\section{Resilience and Resistance of Archaeal Community}

The archaeal abundance showed low resistance as indicated by the negative RS index for NA and AA $(-0.10$ and -0.47 , respectively) (Figure $\mathbf{5 A}$ ). In contrast, the $\mathrm{RL}$ index was as high as 0.40 and 0.78 , respectively, suggesting a higher ability of archaeal abundances to recover from flooding in both areas. All RS indices of alpha diversity in AA (0.29 of Shannon diversity, -0.32 of Chao1 richness, 0.59 of Shannon evenness) were slightly higher than those in NA ( 0.13 of Shannon diversity, -0.32 of Chao1 richness, 0.47 of Shannon evenness). However, the RL indices of alpha diversity in NA (0.33-0.50) were much higher than those in AA (-0.08-0.36), indicating a better recovery of the archaeal diversity in NA.

In an additional step, we compared the RS and RL indices of the four most abundant taxa which included 82.2 and $71.4 \%$ of the total sequences in NA and AA, respectively (Figure 5B). The highest positive RS values in both study areas were obtained for Nitrososphaerales (0.26 and 0.80 in NA and AA, respectively) as the most abundant taxon accounting for 60.9 and $48.1 \%$ of the sequences in NA and AA, respectively. In addition, the most abundant taxon Nitrososphaerales showed a high RL value (0.50) in NA, while it was negative in AA $(-0.29)$. The other three tested taxa (Methanobacterium, Methanosaeta, and Methanosarcina) showed negative RS values and positive RL values whenever they occurred in the respective areas. Finally, sequences considered as unclassified showed negative RS value $(-0.29)$, but rather high RL value (0.67) in AA.

\section{Co-occurrence Patterns of the Archaeal Communities in NA and AA}

We explored the co-occurrence patterns of the archaeal community in NA and AA using network analysis (Figure 6). 


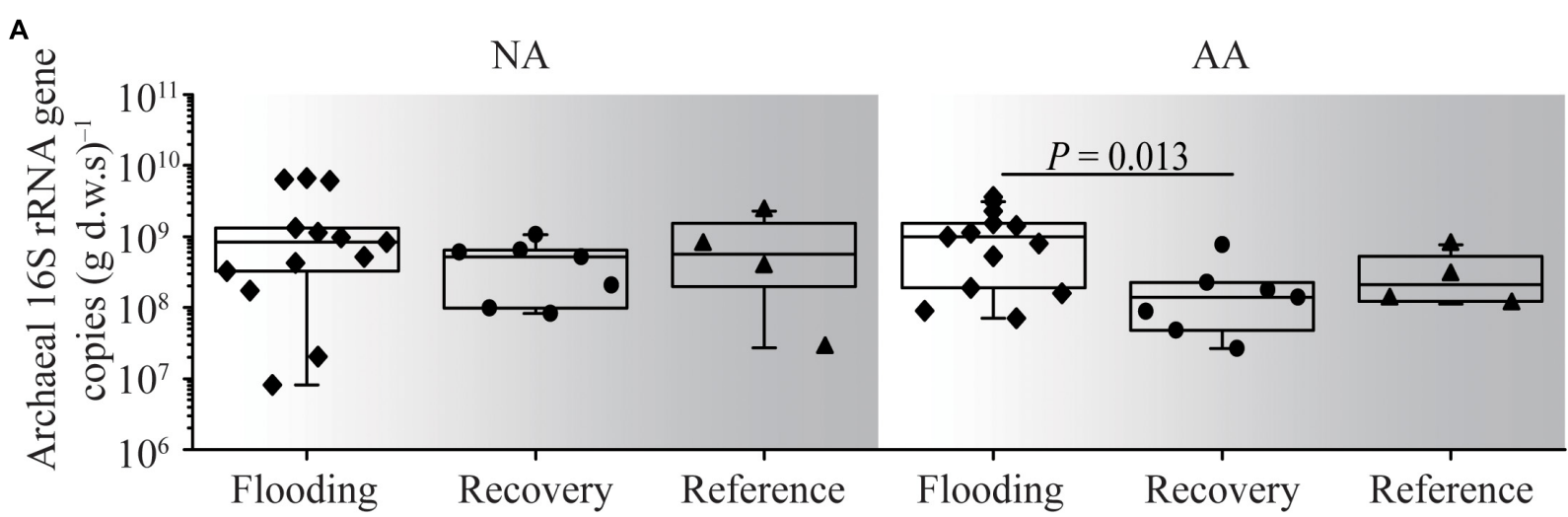

B
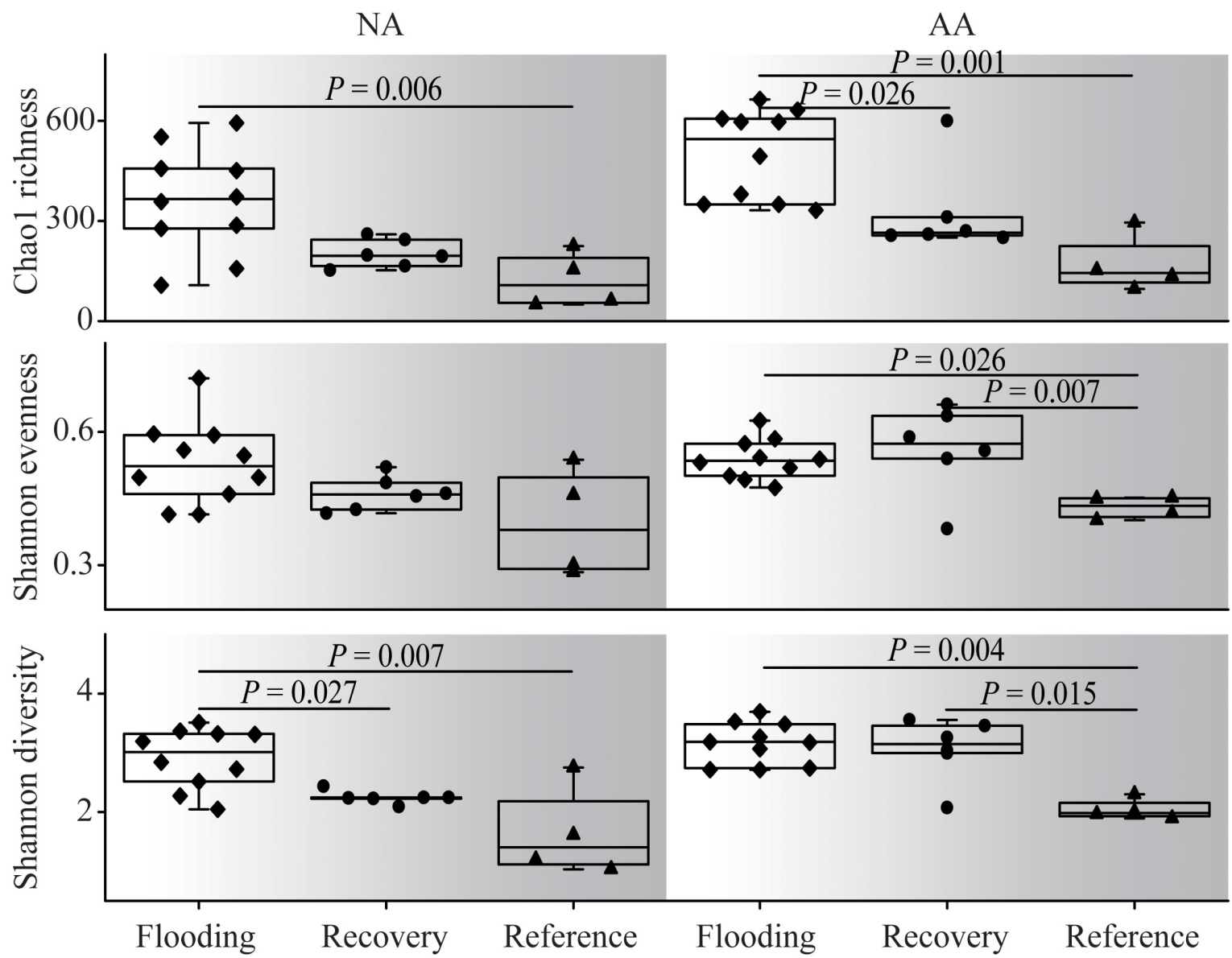

FIGURE 3 | Archaeal abundance (A) and alpha diversity (B) of the flooding, recovery, and reference groups in NA and AA. Significant differences at $P<0.05$ level based on multiple Kruskal-Wallis test were shown.

The two networks showed comparable number of nodes with 24 and 20 in NA and AA, respectively. There were almost double as much edges were observed in the NA networks. Among these edges, 99 positive correlations and 13 negative correlations were observed in NA, while 65 positive and 2 negative correlations were observed in AA. Furthermore, the average degree $(\operatorname{avgK}$, that is the average connectivity of nodes which suggested a more complex network with higher avgK) was greater in the NA network (9.333) than in the AA network (6.700). Other topological properties of the two networks, such as the average path length (that is the average network distance between all pairs of nodes), and the clustering coefficient (i.e., how and what degree nodes tend to cluster together) were very comparable. Finally, the modularity index (that is what 

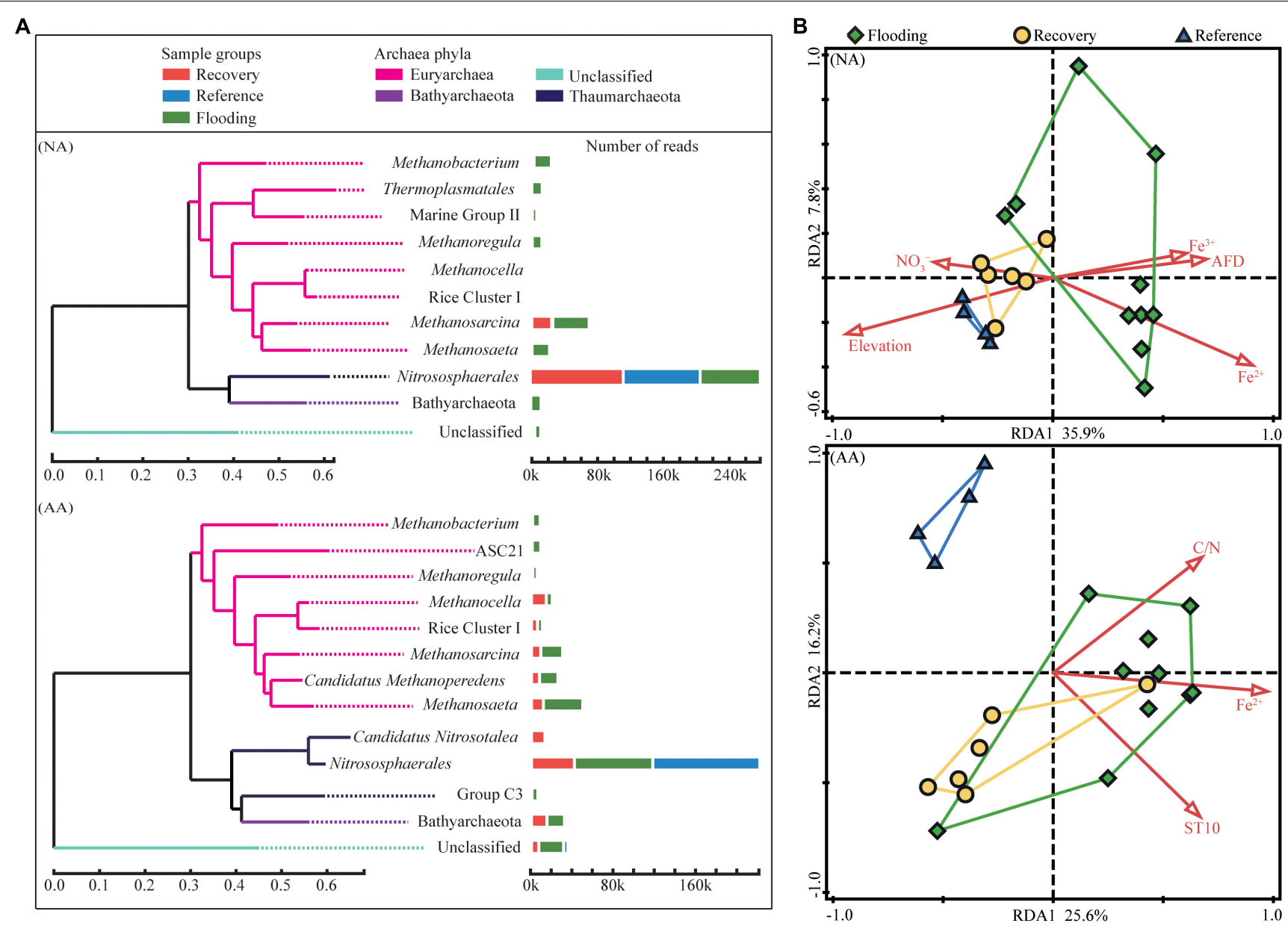

FIGURE 4 | Relative abundance of dominant taxa (relative abundance $>1 \%$ ) in the three sample groups (A), and redundancy analysis of archaeal community structure in NA and AA (B). Colors indicate the sample groups, i.e., flooding (green), recovery (yellow), or reference (blue). The statistically significant $(P<0.05)$ explanatory variables are shown with red arrows.

TABLE 1 | Comparison of community compositions among the three sample groups in NA and AA based on ANOSIM analysis.

\begin{tabular}{llll}
\hline Study area & Comparison & \multicolumn{2}{c}{ ANOSIM $^{\mathbf{a}}$} \\
\cline { 3 - 4 } & & $\boldsymbol{R}$ & $\boldsymbol{P}$ \\
\hline NA & Recovery vs. flooding & $\mathbf{0 . 3 0 7 ^ { \mathbf { b } }}$ & $\mathbf{0 . 0 1 0}$ \\
& Recovery vs. reference & 0.147 & 0.154 \\
& Flooding vs. reference & $\mathbf{0 . 5 0 4}$ & $\mathbf{0 . 0 0 2}$ \\
AA & Recovery vs. flooding & $\mathbf{0 . 2 2 8}$ & $\mathbf{0 . 0 3 3}$ \\
& Recovery vs. reference & $\mathbf{0 . 5 6 4}$ & $\mathbf{0 . 0 1 1}$ \\
& Flooding vs. reference & $\mathbf{0 . 3 4 0}$ & $\mathbf{0 . 0 2 7}$
\end{tabular}

${ }^{a}$ ANOSIM was calculated on OTU level based on Bray-Curtis distance with 999 permutation implying the dissimilarity between two groups. ${ }^{b}$ Significant values are highlighted with bold.

extent a network could be naturally divided) was 0.151 vs. 0.353 in NA and AA. Overall, the co-occurrence networks in the two areas suggested stronger interactions of the archaeal community in NA than AA.

\section{DISCUSSION}

\section{Recovery Ability of Archaea Community}

In this study, the recovery of the archaeal community was assessed by comparing the community structure in different disturbing stages which were flooding (disturbing), recovery, and reference. No significant impact of flooding on total archaeal abundance was observed. As a whole, the abundance of archaea has a strong ability to resist disturbance, which is probably due to, on the one hand, a high adaptation to diverse and stressful conditions of archaea, either by their low-permeability membranes or specific catabolic pathways (Valentine, 2007); on the other hand, high functional diversity of archaea, for instance, Euryarchaeota emerge in anaerobic conditions ( $\mathrm{Hu}$ et al., 2013), and aerobic conditions increase the number of the Thaumarchaeota (Pester et al., 2011), eventually maintain the abundance at a stable level. It was coincident to a certain extent that the relative abundance of Euryarchaeota (52.0 and $44.2 \%$ in NA and AA, respectively) was highest in flooding group, whereas Thaumarchaeota (95.9 and $93.6 \%$ in NA and 


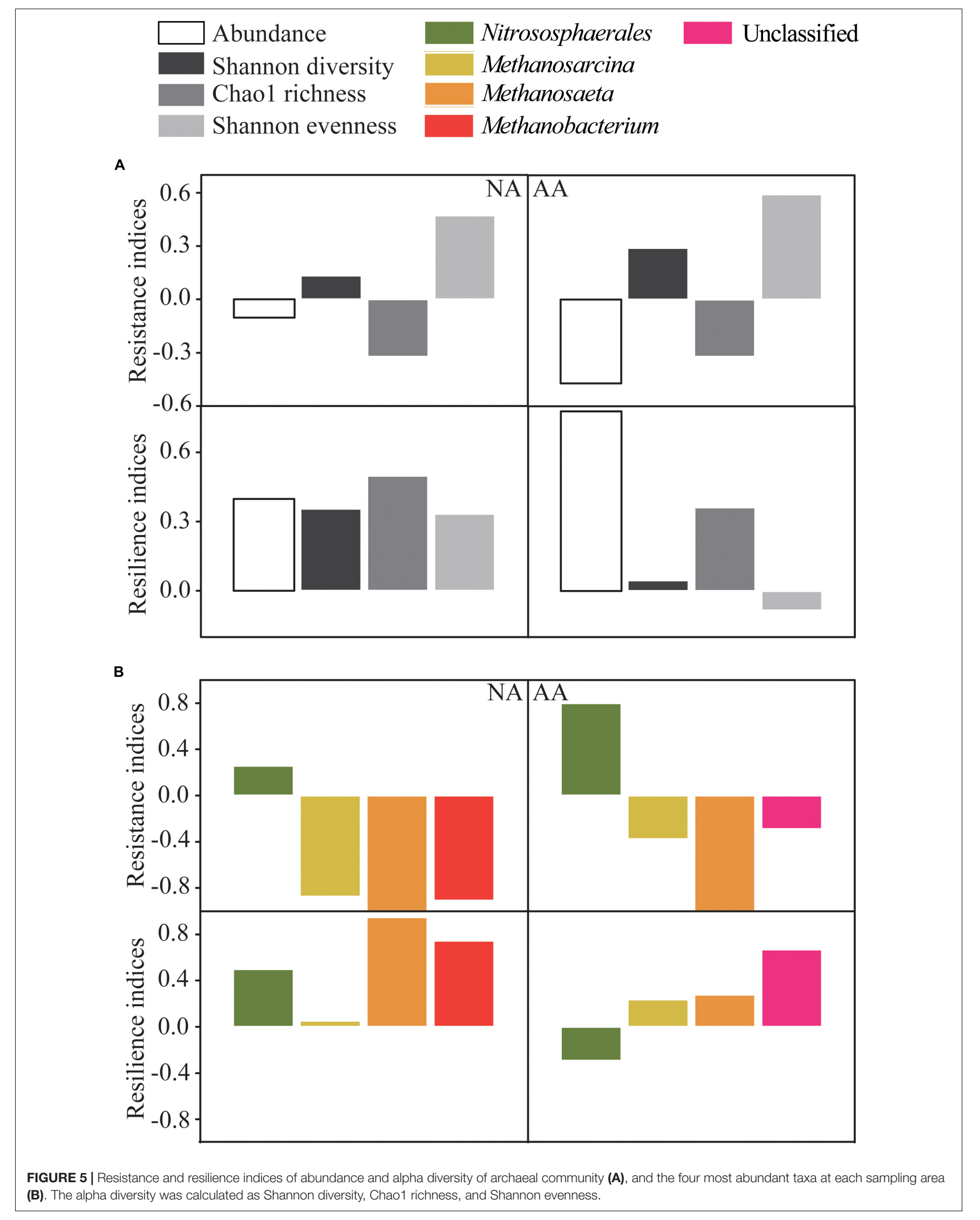




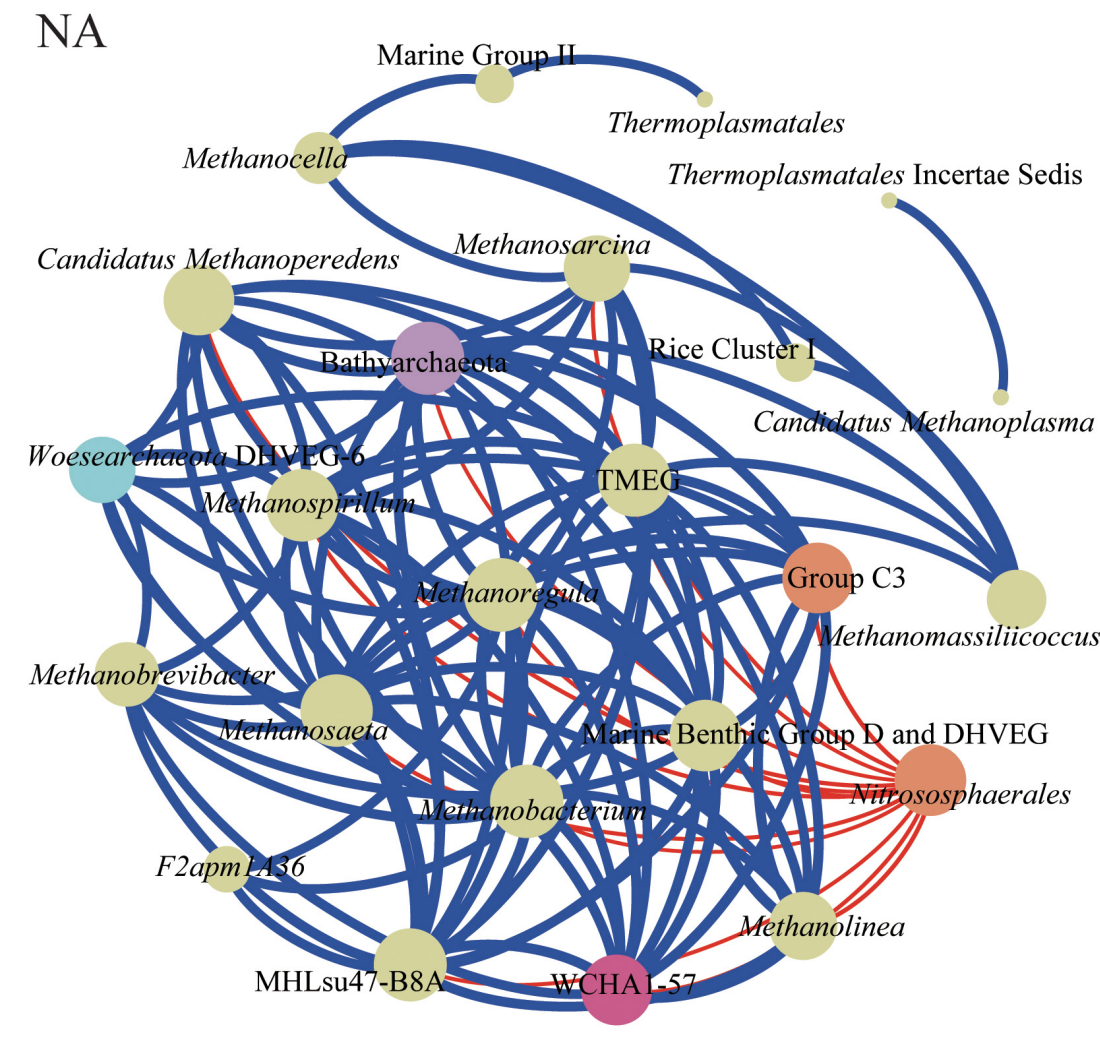

AA

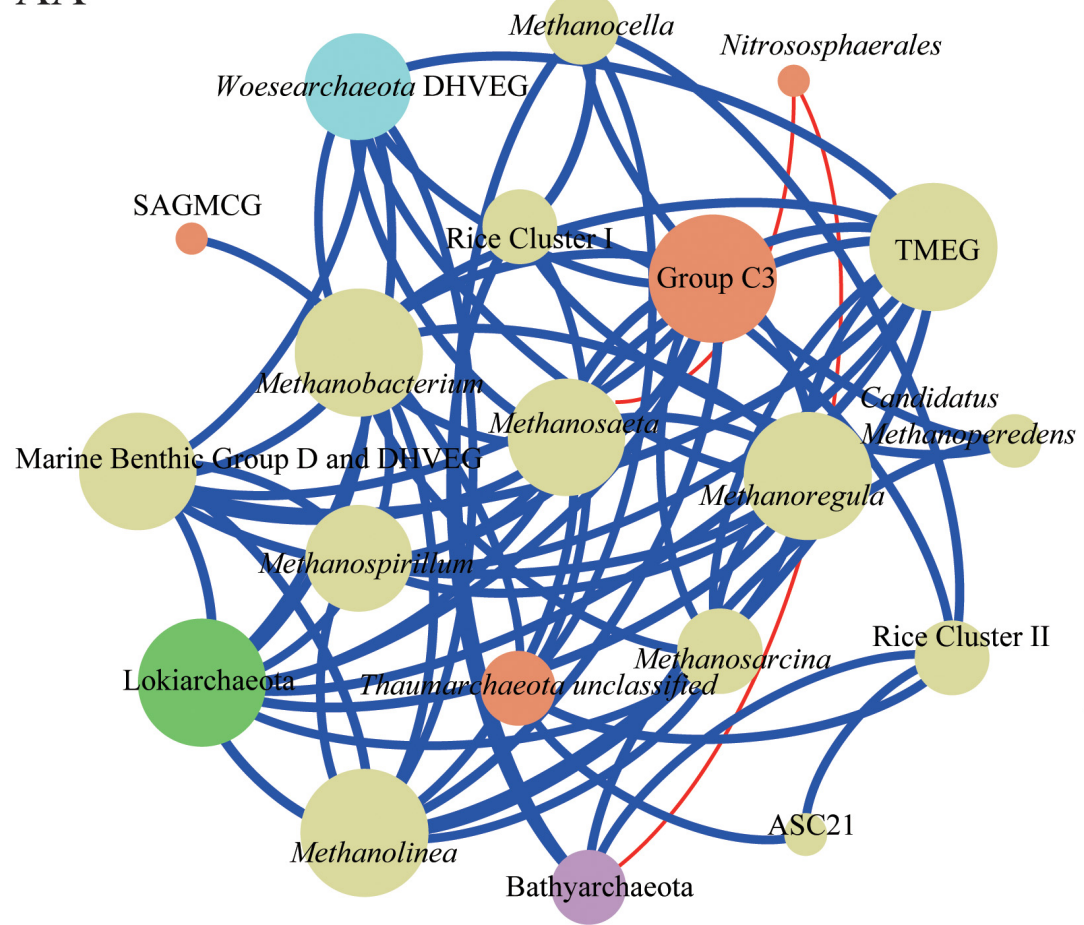

Colors of nodes

Euryarchaeota

- Thaumarchaeota

Bathyarchaeota

Woesearchaeota

WSA2

Lokiarchaeota

Topological properties of network BJX:

Number of nodes 24

Number of edges $\quad 112$

Number of positive correlations $\quad 99$

Number of negative correlations 13

Average degree $\quad 9.333$

Network diameter 4

Graph density $\quad 0.203$

Modularity $\quad 0.151$

Number of modules 5

Average clustering coefficient $\quad 0.337$

Average path length $\quad 1.327$

Topological properties of network XH:

Number of nodes 20

Number of edges $\quad 67$

Number of positive correlations $\quad 65$

Number of negative correlations 2

Average degree $\quad 6.700$

Network diameter 3

Graph density $\quad 0.176$

Modularity $\quad 0.353$

Number of modules 2

Average clustering coefficient $\quad 0.375$

Average path length $\quad 1.250$

FIGURE 6 | Co-occurring network of archaeal communities in NA and AA based on correlation analysis. The nodes in network are colored by phylum. The connections in the network indicate strong $(\rho>0.6)$ and significant $(P<0.01)$ correlations. The size of each node in proportion to the number of connections (i.e., degree); the thickness of each connection between two nodes (i.e., edge) in proportion to the Spearman's correlation coefficient. A blue edge indicates a positive interaction between two individual nodes, while a red edge indicates a negative interaction. 
AA, respectively) was highest in reference group (Supplementary Figure S4). Moreover, the flooding groups in both NA and AA had the most abundant euryarchaeotal methanogens (47.6 and $34.6 \%$ in relative abundance), and the least ammonia-oxidizing archaea (38.9 and $35.6 \%$ in relative abundance) compared with the reference and recovery groups (Supplementary Figure S3). It can be expected that the flooding disturbance may increase methane generation but decrease ammonia oxidation.

In contrast, the community diversity, which is a parameter frequently associated with the ecosystem stability (Tilman et al., 2006; Wang and Loreau, 2016), appeared to be more sensitive to the disturbances. Although the flooding significantly increased the alpha diversity, the diversity in the recovery group showed a tendency to return to the predisturbance level (reference group) after the flooding receded. It was very obvious from the NA samples which showed comparable Shannon diversity level in the recovery and reference groups. Studies performed within coal mine have identified that microbial community with good recovery ability harbor comparable diversity level in both recovery and reference soils (Li et al., 2014; Quadros et al., 2016). Therefore, a better recovery of archaeal community in NA was supported by the relatively close values of diversity between the recovery and reference groups. Similar patterns were also observed in the community composition in $\mathrm{NA}$, in which the recovery group was different from the flooding group but was relatively similar with the reference group (Table 1). The RDA plot further demonstrated that the community compositions in NA were clustered together by the sample groups. The distributions of archaeal community compositions were significantly impacted by the variables $\left(\mathrm{NO}_{2}^{-}, \mathrm{Fe}^{2+}\right.$, and flooding duration) closely related to the elevation. By contrast, less variables significantly impacted the community composition in AA indicating more factors in addition to the measured variables also shaping the community composition.

\section{Anthropogenic Impact of Archaea Recovery}

As two basic properties of ecological stability, resistance and resilience were pervasive in evaluating the response of microorganisms to disturbance (Thion and Prosser, 2014; Ng et al., 2015; Chen et al., 2017). By calculating resistance (RS) and resilience (RL) indices, we found that the RS index of archaeal abundance was negative in both sampling areas, hence, it can be concluded that the relative stability of archaeal abundance was mostly ascribed to the high resilience. Similarly, the better recovery of diversity in NA was also associated with its high resilience. The Nitrososphaerales was the dominant phylotype of archaea in a wide variety of environments (Bates et al., 2011) and represented almost half of the retrieved sequences in this study. As a key component, the recovery of the Nitrososphaerales was important for the entire archaeal community. Since the RS values were comparable in the two areas, the better recovery of the archaeal community composition in NA was probably ascribed to the higher RL values of the Nitrososphaerales. Therefore, it is speculated that the ammonia oxidation by archaea in the riparian zone might be substantial playing an important role in nitrogen removal in the TGR.

Co-occurrence networks are used to infer potential ecological associations between organisms and are useful tools to assess the ecosystem stability for a long time (May, 1972; Pimm, 1984; Montoya et al., 2006). The co-occurrence network in NA showed more complex associations. The number of edges (significant interactions, $P<0.01)$, average degree $(\operatorname{avgK})$, average path length, and diameter of the network in NA were higher than those in AA. Previous studies proposed that the existence of species of a higher association with each another significantly increased both resistance and resilience against perturbation (May, 1972; Stouffer and Bascompte, 2011). This proposition was further identified in microbial ecology that the highly complex networks meant high resistance to disturbances and could be used to indicate ecosystem stability (Peura et al., 2015). Hence, the higher degree of species association and complex network in NA might indicate a more stable community. The diversity was a very common indicator to predict ecosystem stability (Tilman et al., 2006; Wang and Loreau, 2016). However, the two study areas, which had distinct recovery property, did not show obvious difference concerning diversity (Figure 3). Therefore, we could infer that the diversity cannot be a sign of ecosystem stability on its own. The association between species, as showed in the networks, would be of certain importance.

The recovery ability of archaea community in AA was weaker than in NA probably associated with the higher pollution level in AA. It has been reported that the resilience of methane oxidation activity was observed only at low pollution level, while microbial diversity was decreased and no recovery was observed at high level of pollution (Deng et al., 2011). Besides, a combined effect of disturbances may also reduce the recovery of microbial community. A previous study showed that respiration of soils contaminated with metals was very sensitive to subsequent heat or salt disturbances, which proves that disturbed systems have less energy to deal with additional disturbances (ToborKapłon et al., 2006). Thus, microorganisms from highly polluted soils have lowered resources due to the energy consumption of detoxification and damage repair caused by the first disturbance, making it hard to deal with any additional disturbance (Calow, 1991; Kuperman and Carreiro, 1997). Therefore, the soil in NA exhibited a better recovery compared to that in AA where both flooding and anthropogenic pollution occurred. These results suggested that archaeal communities in the riparian soils have the ability of autogenic recovery from water flooding, whereas the autogenic recovery process would be intervened by human impact.

\section{Significance to Reservoir Ecosystem}

The full operation of the TGR has resulted in periodic disturbances of water level fluctuation to the riparian zone. Currently, the original terrestrial ecosystem is at an early stage of secondary succession resulting in the extinction of local plant species and reduction of diversity (Bao et al., 2015). In the meantime, the microbial community, which is a key component of the riparian ecosystem, is also in a process of adaptation to the changed environmental conditions. It can be 
foreseen that this adaptation would eventually lead to a more stable community in response to the disturbance, which has been shown in other studies (Garcia-Villaraco Velasco et al., 2009; Stres et al., 2010). A stable and high resilience microbial community is of great significance in re-establishing ecosystem functioning during restoration (Harris, 2009), because of the role in regulating biogeochemical cycles (Griffiths and Philippot, 2013). However, there was usually a threshold intensity above which the microbial community could never recover and turn to alternative states (Gao et al., 2011; Griffiths and Philippot, 2013). The archaeal community in the riparian zone of the TGR has the ability to recover from flooding disturbance like in NA embedded in the context of low anthropogenic pollution, rather than in AA with a higher human impact. Moreover, high anthropogenic pollution levels may accelerate the methane production, whereas weaken the ammonia oxidation in the riparian zone. Therefore, in the recovery process, great efforts should be made to avoid human interference from outside scale, to facilitate the autogenic succession of the riparian ecosystem achieving high ecosystem stability.

\section{DATA AVAILABILITY STATEMENT}

The datasets generated for this study can be found in NCBI Sequence Read Archive, PRJNA394057.

\section{REFERENCES}

Allison, S. D., and Martiny, J. B. H. (2008). Resistance, resilience, and redundancy in microbial communities. Proc. Natl. Acad. Sci. U.S.A. 105, 11512-11519. doi: $10.1073 /$ pnas.0801925105

Bao, S. D. (2000). Chemical Analysis for Agricultural Soil. Beijing, China: China Agriculture Press.

Bao, Y. H., Gao, P., and He, X. B. (2015). The water-level fluctuation zone of Three Gorges Reservoir-a unique geomorphological unit. Earth Sci. Rev. 150, 14-24. doi: 10.1016/j.earscirev.2015.07.005

Bapiri, A., Bååth, E., and Rousk, J. (2010). Drying-rewetting cycles affect fungal and bacterial growth differently in an arable soil. Microb. Ecol. 60, 419-428. doi: 10.1007/s00248-010-9723-5

Bastian, M., Heymann, S., and Jacomy, M. (2009). "Gephi: an open source software for exploring and manipulating networks," in Proceedings of the International AAAI Conference on Weblogs and Social Media, San Jose, CA.

Bates, S. T., Berg-lyons, D., Caporaso, J. G., Walters, W. A., Knight, R., and Fierer, N. (2011). Examining the global distribution of dominant archaeal populations in soil. ISME J. 5, 908-917. doi: 10.1038/ismej.20 10.171

Bernd, W., Franziska, W., and Rolf, D. (2012). RNA-based assessment of diversity and composition of active archaeal communities in the German Bight. Archaea 2012:695826. doi: 10.1155/2012/695826

Birch, H. F. (1958). The effect of soil drying on humus decomposition and nitrogen availability. Plant Soil 10, 9-31. doi: 10.1007/BF01343734

Burger, M., Jackson, L. E., Lundquist, E. J., Louie, D. T., Miller, R. L., Rolston, D. E., et al. (2005). Microbial responses and nitrous oxide emissions during wetting and drying of organically and conventionally managed soil under tomatoes. Biol. Fert. Soils 42, 109-118. doi: 10.1007/s00374-005-0007-z

Burggraf, S., Huber, H., and Stetter, K. O. (1997). Reclassification of the crenarchael orders and families in accordance with 16S rRNA sequence data. Int. J. Syst. Bacteriol. 47, 657-660. doi: 10.1099/00207713-473-657

\section{AUTHOR CONTRIBUTIONS}

YW, SW, GZ, and WZ designed the study. FY and MM performed the field work and laboratory work. YW, YH, and FY analyzed the data. YW and FY wrote the manuscript. HO contributed to the writing. All authors reviewed the manuscript.

\section{FUNDING}

This work was supported by the National Natural Science Foundation of China (Grant Numbers 41977153, 51908145, 51779241, 31870100, and 91851111) and Youth Innovation Promotion Association of CAS (2015316).

\section{ACKNOWLEDGMENTS}

The authors thank Mingquan Lv, Yi Jiang, and Yuanyang Huang at the Chongqing Institute of Green and Intelligent Technology, Chinese Academy of Sciences for the assistance in sampling.

\section{SUPPLEMENTARY MATERIAL}

The Supplementary Material for this article can be found online at: https://www.frontiersin.org/articles/10.3389/fmicb. 2019.02285/full\#supplementary-material

Calow, P. (1991). Physiological costs of combating chemical toxicants: ecological implications. Comp. Biochem. Phys. C 100, 3-6. doi: 10.1016/0742-8413(91) 90110-F

Chen, J., Nie, Y. X., Liu, W., Wang, Z. F., and Shen, W. J. (2017). Ammoniaoxidizing archaea are more resistant than denitrifiers to seasonal precipitation changes in an acidic subtropical forest soil. Front. Microbiol. 8:1384. doi: 10. 3389/fmicb.2017.01384

China Three Gorges Corporation (2017). Brief Introduction of Three Gorges Corporation. Available at: https://www.ctg.com.cn/sxjt/sxgc4/gcgk7/index.html (accessed March 1, 2017).

Dean, W. E. (1974). Determination of carbonate and organic matter in calcareous sediments and sedimentary rocks by loss on ignition: comparison with other methods. J. Sediment. Res. 44, 242-248. doi: 10.1306/74D729D2-2B21-11D7$8648000102 \mathrm{C} 1865 \mathrm{D}$

Deng, H., Guo, G. X., and Zhu, Y. G. (2011). Pyrene effects on methanotroph community and methane oxidation rate, tested by dose-response experiment and resistance and resilience experiment. J. Soil. Sediment. 11, 312-321. doi: 10.1007/s11368-010-0306-3

Faust, K., and Raes, J. (2012). Microbial interactions: from networks to models. Nat. Rev. Microbiol. 10, 538-550. doi: 10.1038/nrmicro2832

Gao, Y., Zhong, B. L., Yue, H., Wu, B., and Cao, S. X. (2011). A degradation threshold for irreversible loss of soil productivity: a long-term case study in China. J. Appl. Ecol. 48, 1145-1154. doi: 10.1111/j.1365-2664.2011.02011.x

Garcia-Villaraco Velasco, A., Probanza, A., Gutierrez Mañero, F. J., Cruz Treviño, A., Moreno, J. M., and Lucas Garcia, J. A. (2009). Effect of fire and retardant on soil microbial activity and functional diversity in a Mediterranean pasture. Geoderma 153, 186-193. doi: 10.1016/j.geoderma.2009.08.005

Glasby, T. M., and Underwood, A. J. (1996). Sampling to differentiate between pulse and press perturbations. Environ. Monit. Assess. 42, 241-252. doi: 10. 1007/bf00414371

Griffiths, B. S., and Philippot, L. (2013). Insights into the resistance and resilience of the soil microbial community. FEMS Microbiol. Rev. 37, 112-129. doi: 10. 1111/j.1574-6976.2012.00343.x 
Großkopf, R., Stubner, S., and Liesack, W. (1998). Novel euryarchaeotal lineages detected on rice roots and in the anoxic bulk soil of flooded rice microcosms. Appl. Environ. Microbiol. 64, 4983-4989.

Harris, J. A. (2003). Measurements of the soil microbial community for estimating the success of restoration. Eur. J. Soil Sci. 54, 801-808. doi: 10.1046/j.1365-2389. 2003.00559.x

Harris, J. A. (2009). Soil microbial communities and restoration ecology: facilitators or followers? Science 325, 573-574. doi: 10.1126/science.1172975

Hartmann, M., Niklaus, P. A., Zimmermann, S., Schmutz, S., Kremer, J., Abarenkov, K., et al. (2014). Resistance and resilience of the forest soil microbiome to logging-associated compaction. ISME J. 8, 226-244. doi: 10. 1038/ismej.2013.141

Hu, H. W., Zhang, L. M., Yuan, C. L., and He, J. Z. (2013). Contrasting Euryarchaeota communities between upland and paddy soils exhibited similar pH-impacted biogeographic patterns. Soil Biol. Biochem. 64, 18-27. doi: 10. 1016/j.soilbio.2013.04.003

Hu, X., Du, H., Ren, C., and Xu, Y. (2016). Illuminating anaerobic microbial community and co-occurrence patterns across a quality gradient in Chinese liquor fermentation pit muds. Appl. Environ. Microbiol. 82, 2506-2515. doi: 10.1128/AEM.03409-15

Kuperman, R. G., and Carreiro, M. M. (1997). Soil heavy metal concentrations, microbial biomass and enzyme activities in a contaminated grassland ecosystem. Soil Biol. Biochem. 29, 179-190. doi: 10.1016/S0038-0717(96) 00297-0

Lee, S. H., Sorensen, J. W., Grady, K. L., Tobin, T. C., and Shade, A. (2017). Divergent extremes but convergent recovery of bacterial and archaeal soil communities to an ongoing subterranean coal mine fire. ISME J. 11, 1447-1459. doi: 10.1038/ismej.2017.1

Lewis, D. E., White, J. R., Wafula, D., Athar, R., Dickerson, T., Williams, H. N., et al. (2010). Soil functional diversity analysis of a bauxite-mined restoration chronosequence. Microb. Ecol. 59, 710-723. doi: 10.1007/s00248-009-9621-x

Li, Y. Y., Wen, H. Y., Chen, L. Q., and Yin, T. T. (2014). Succession of bacterial community structure and diversity in soil along a chronosequence of reclamation and re-vegetation on coal mine spoils in China. PLoS One 9:e115024. doi: 10.1371/journal.pone.0115024

Ma, B., Wang, H. Z., Dsouza, M., Lou, J., Yan, H., Dai, Z. M., et al. (2016). Geographic patterns of co-occurrence network topological features for soil microbiota at continental scale in eastern China. ISME J. 10, 1891-1901. doi: 10.1038/ismej.2015.261

May, R. M. (1972). Will a large complex system be stable? Nature 238, 413-414. doi: $10.1038 / 238413 \mathrm{a} 0$

Meyer, A. F., Lipson, D. A., Martin, A. P., Schadt, C. W., and Schmidt, S. K. (2004). Molecular and metabolic characterization of cold-tolerant alpine soil Pseudomonas sensu stricto. Appl. Environ. Microbiol. 70, 483-489. doi: 10.1128/ Aem.70.1.483-489.2004

Montoya, J. M., Pimm, S. L., and Sole, R. V. (2006). Ecological networks and their fragility. Nature 442, 259-264. doi: 10.1038/nature04927

Ng, E. L., Patti, A. F., Rose, M. T., Schefe, C. R., Smernik, R. J., and Cavagnaro, T. R. (2015). Do organic inputs alter resistance and resilience of soil microbial community to drying? Soil Biol. Biochem. 81, 58-66. doi: 10.1016/j.soilbio.2014. 10.028

Nilsson, C., Reidy, C. A., Dynesius, M., and Revenga, C. (2005). Fragmentation and flow regulation of the world's large river systems. Science 308, 405-408. doi: $10.1126 /$ science. 1107887

Orwin, K. H., and Wardle, D. A. (2004). New indices for quantifying the resistance and resilience of soil biota to exogenous disturbances. Soil Biol. Biochem. 36, 1907-1912. doi: 10.1016/j.soilbio.2004.04.036

Pester, M., Schleper, C., and Wagner, M. (2011). The Thaumarchaeota: an emerging view of their phylogeny and ecophysiology. Curr. Opin. Microbiol. 14, 300-306. doi: 10.1016/j.mib.2011.04.007

Peura, S., Bertilsson, S., Jones, R. I., and Eiler, A. (2015). Resistant microbial cooccurrence patterns inferred by network topology. Appl. Environ. Microbiol. 81, 2090-2097. doi: 10.1128/Aem.03660-14

Pimm, S. L. (1984). The complexity and stability of ecosystems. Nature 307, 321-326. doi: 10.1038/307321a0

Quadros, P. D. D., Zhalnina, K., Davis-Richardson, A. G., Drew, J. C., Menezes, F. B., Camargo, F. A. D. O., et al. (2016). Coal mining practices reduce the microbial biomass, richness and diversity of soil. Appl. Soil Ecol. 98, 195-203. doi: 10.1016/j.apsoil.2015.10.016
Shi, R. J. (2011). Ecological environment problems of the Three Gorges Reservoir Area and countermeasures. Procedia Environ. Sci. 10, 1431-1434. doi: 10.1016/ j.proenv.2011.09.228

Sponseller, R. A. (2007). Precipitation pulses and soil $\mathrm{CO}^{2}$ flux in a Sonoran Desert ecosystem. Glob. Change Biol. 13, 426-436. doi: 10.1111/j.1365-2486. 2006.01307.x

Stouffer, D. B., and Bascompte, J. (2011). Compartmentalization increases foodweb persistence. Proc. Natl. Acad. Sci. U.S.A. 108, 3648-3652. doi: 10.1073/pnas. 1014353108

Stres, B., Philippot, L., Faganeli, J., and Tiedje, J. M. (2010). Frequent freeze-thaw cycles yield diminished yet resistant and responsive microbial communities in two temperate soils: a laboratory experiment. FEMS Microbiol. Ecol. 74, 323-335. doi: 10.1111/j.1574-6941.2010.00951.x

Su, W. C., and Zhang, J. Y. (2010). The main eco-environmental problems and prevent measures within the watercourse-type fluctuation zone - a case in Chongqing reach of the Three Gorges Reservoir. Carsol. Sin. 29, 445-450. doi: 10.3969/j.issn.1001-4810.2010.04.016

Thion, C., and Prosser, J. I. (2014). Differential response of nonadapted ammoniaoxidising archaea and bacteria to drying-rewetting stress. FEMS Microbiol. Ecol. 90, 380-389. doi: 10.1111/1574-6941.12395

Tilman, D., Reich, P. B., and Knops, J. M. H. (2006). Biodiversity and ecosystem stability in a decade-long grassland experiment. Nature 441, 629-632. doi: 10. 1038/nature 04742

Tobor-Kapłon, M. A., Bloem, J., and de Ruiter, P. C. (2006). Functional stability of microbial communities from long-term stressed soils to additional disturbance. Environ. Toxicol. Chem. 25, 1993-1995. doi: 10.1897/05-398R1.1

Valentine, D. L. (2007). Adaptations to energy stress dictate the ecology and evolution of the Archaea. Nat. Rev. Microbiol. 5, 316-323. doi: 10.1038/ nrmicro1619

van der Heijden, M. G. A., Bardgett, R. D., and van Straalen, N. M. (2008). The unseen majority: soil microbes as drivers of plant diversity and productivity in terrestrial ecosystems. Ecol. Lett. 11, 296-310. doi: 10.1111/j.1461-0248.2007. 01139.x

van Dijk, J., Didden, W. A. M., Kuenen, F., van Bodegom, P. M., Verhoef, H. A., and Aerts, R. (2009). Can differences in soil community composition after peat meadow restoration lead to different decomposition and mineralization rates? Soil Biol. Biochem. 41, 1717-1725. doi: 10.1016/j.soilbio.2009.05.016

Vellend, M. (2010). Conceptual synthesis in community ecology. Q. Rev. Biol. 85, 183-206. doi: 10.1086/652373

Wang, S., and Loreau, M. (2016). Biodiversity and ecosystem stability across scales in metacommunities. Ecol. Lett. 19, 510-518. doi: 10.1111/ele.12582

Wang, Y., Huang, P., Ye, F., Jiang, Y., Song, L. Y., Op den Camp, H. J. M., et al. (2016). Nitrite-dependent anaerobic methane oxidizing bacteria along the water level fluctuation zone of the Three Gorges Reservoir. Appl. Microbiol. Biot. 100, 1977-1986. doi: 10.1007/s00253-015-7083-2

Wardle, D. A., Bardgett, R. D., Klironomos, J. N., Setälä, H., van der Putten, W. H., and Wall, D. H. (2004). Ecological linkages between aboveground and belowground biota. Science 304, 1629-1633. doi: 10.1126/science.109 4875

Wu, H. P., Zeng, G. M., Liang, J., Guo, S. L., Dai, J., Lu, L. H., et al. (2015). Effect of early dry season induced by the Three Gorges Dam on the soil microbial biomass and bacterial community structure in the Dongting Lake wetland. Ecol. Indic. 53, 129-136. doi: 10.1016/j.ecolind.2015.01.041

Xian, G., Fang, Z. D., and Long, X. Y. (2013). Investigation on ecological problems water-lever-fluctuating zone in Three Gorges Reservoir Region. Environ. Sci. Manage. 38, 67-69. doi: 10.3969/j.issn.1673-1212.2013. 02.018

Xu, X. B., Tan, Y., Yang, G. S., Li, H. P., and Su, W. Z. (2011). Impacts of China's Three Gorges Dam Project on net primary productivity in the reservoir area. Sci. Total Environ. 409, 4656-4662. doi: 10.1016/j.scitotenv.2011.08.004

Yannarell, A. C., Steppe, T. F., and Paerl, H. W. (2007). Disturbance and recovery of microbial community structure and function following Hurricane Frances. Environ. Microbiol. 9, 576-583. doi: 10.1111/j.1462-2920.2006.01173.x

Ye, C., Li, S. Y., Yang, Y. Y., Xiao, S., Zhang, J. Q., and Zhang, Q. F. (2015). Advancing analysis of spatio-temporal variations of soil nutrients in the water level fluctuation zone of China's Three Gorges Reservoir using self-organizing map. PLoS One 10:e0121210. doi: 10.1371/journal.pone.0121210

Ye, F., Ma, M. H., Wu, S. J., Jiang, Y., Zhu, G. B., Zhang, H., et al. (2019). Soil properties and distribution in the riparian zone: the effects of fluctuations 
in water and anthropogenic disturbances. Eur. J. Soil Sci. 70, 664-673. doi: $10.1111 /$ ejss. 12756

Ye, F., Wu, S. J., Jiang, Y., Op den Camp, H. J. M., Li, Z., Zhu, G. B., et al. (2016). Shifts of archaeal community structure in soil along an elevation gradient in a reservoir water level fluctuation zone. J. Soil. Sediment. 16, 2728-2739. doi: 10.1007/s11368-016$1485-3$

Zheng, G. D., Takano, B., Kuno, A., and Matsuo, M. (2001). Iron speciation in modern sediment from Erhai Lake, southwestern China: redox conditions in an ancient environment. Appl. Geochem. 16, 1201-1213. doi: 10.1016/S08832927(01)00016-6
Conflict of Interest: The authors declare that the research was conducted in the absence of any commercial or financial relationships that could be construed as a potential conflict of interest.

Copyright (c) 2019 Wang, Hong, Ma, Wu, Op den Camp, Zhu, Zhang and Ye. This is an open-access article distributed under the terms of the Creative Commons Attribution License (CC BY). The use, distribution or reproduction in other forums is permitted, provided the original author(s) and the copyright owner(s) are credited and that the original publication in this journal is cited, in accordance with accepted academic practice. No use, distribution or reproduction is permitted which does not comply with these terms. 